\title{
Elementos-chave de uma teoria da sociedade mundial*
}

Recebido: 18.04 .18

Aprovado: 13.06.18

Rudolf Stichweh**

Resumo: Esse artigo oferece uma visão geral dos insights necessários para se construir uma teoria da sociedade mundial. A seção 1 define o conceito de sociedade e busca identificar tipos diferentes de sociedade que podem ser observados na história dos sistemas sociais humanos; 2 conecta o argumento sobre a sequência de tipos de sociedade com uma reconstrução dos padrões de povoamento da Terra por grupos de humanos; e 3 apresenta um conceito geral de evolução sociocultural como o processo básico de formação das sociedades. O artigo então muda seu foco para a formação da sociedade mundial moderna como a forma contemporânea da sociedade (séculos XVIII ao XXI) e 4 define os principais aspectos da complexidade do sistema mundial e o nexo com a diferenciação funcional; 5 identifica as revoluções inclusivas que ocorrem desde o século XVIII como pontos de partida dos sistemas de função global como a economia, a educação, a ciência e as instituições políticas, e 6 explica a inter-relação dos sistemas de função a outras autoestruturas (Eigenstructures) emergentes da sociedade mundial (as redes globais, organizações globais, comunidades epistêmicas e sistemas de interação global); finalmente, 7 debruça-se sobre mecanismos básicos da globalização - a saber, comunicação, migração, observação e conhecimento.

Palavras-chave: Sistema mundial. Evolução sociocultural. Complexidade global. Diferenciação funcional. Mecanismos de globalização.

\section{Key elements of a theory of world society}

Abstract: The paper gives an overview of the most important insights one needs to construct a theory of world society. The paper 1 defines the concept of society and tries to find out how many different types of society are to be observed in the history of human social systems, 2 connects the argument about the sequence of types of society with a reconstruction of the patterns of the settlement of the earth by groups of humans and 3 resumes these arguments by presenting a general concept of sociocultural evolution as the basic process of the formation of societies. The paper then switches its focus to a reconstruction of modern world society as the contemporary form of society (18th-21st Centuries) and 4 defines the main aspects of the complexity of the world system and the nexus to functional differentiation, 5 identifies the inclusion revolutions since the 18th century as the starting point of global function systems such as the economy, education, science and polity, and 6 explains the interrelation of function systems and the other emerging Eigenstructures of world society (global networks, global organizations, epistemic communities, global interaction systems) and finally 7 works out the basic mechanisms of globalization - namely communication, migration, observation and knowledge.

Keywords: World system. Sociocultural evolution. Global complexity. Functional differentiation. Globalization mechanisms.

\author{
* Tradução: Diogo \\ Saraiva. \\ ** Rudolf Stichweh \\ é diretor do Forum \\ Internationale \\ Wissenschaft \\ e Dahrendorf \\ Professorship \\ de teoria da \\ sociedade moderna. \\ Universidade \\ de Bonn, Bonn, \\ Alemanha. \\ <rstichweh@yahoo. \\ de>.
}




\section{O que é sociedade e que tipos de sociedade observamos?}

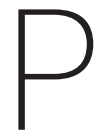

ara entendermos a sociedade mundial, devemos primeiramente ter uma ideia sobre o sentido do conceito de sociedade. Parece existir consenso implícito de que a sociedade é sempre o macrossistema mais extenso que inclui uma rede fechada de relações sociais, formando um sistema que produz todas as estruturas e todos os processos que a constituem em suas próprias fronteiras, com base em seus próprios recursos. Essa noção se aproxima dos entendimentos explícitos formulados por Talcott Parsons e Niklas Luhmann (Stichweh, 2005). Além do fechamento e da autorreprodução, é possível agregar ideias sobre a autossuficiência e autarquia, que já se destacavam na teoria política dos antigos gregos. 0 pensamento iluminista apontava para uma tendência a expansão como princípio formativo de uma sociedade:

O princípio social no homem é de uma natureza tão expansiva que não pode ser confinada ao circuito de uma família, de amigos, de um bairro; ele [...] os impele a comunidades e nações cada vez maiores (Britanica, 1771).

Existem vários tipos de sociedade na história dos sistemas sociais humanos. Por dezenas de milhares de anos (aproximadamente de 70.000-10.000 a.C.) existiram apenas sociedades de caçadores/coletores, que consistiam de algumas dezenas até no máximo algumas centenas de membros. Eram sociedades móveis, migratórias, que se deslocavam quando seus recursos nutritivos já não eram suficientes para o sustento de suas necessidades. As sociedades sedentárias surgem conjuntamente com a agricultura, há cerca de 10.000 anos, agregando papéis e instituições políticas e religiosas, podendo ser descritas, a partir de certo ponto, como Estados politicamente unificados.

A partir da expansão territorial dos Estados, surgiram sociedades mais extensas que, por meio da acumulação militar e de mínimo controle político, incluíram várias sociedades caçadoras/coletoras e alguns Estados dentro de uma macrossociedade, muitas vezes chamada de império. Os Impérios, que já podiam cobrir extensões territoriais de milhares de quilômetros, existiram por seis mil anos até os tempos atuais, quando a maior parte deles desapareceu após a Segunda Guerra Mundial, com a ascensão final do Estado nacional e territorial como a forma política dominante da sociedade mundial.

Paralelamente à expansão dos impérios, pode-se observar o que foi possivelmente um tipo de sociedade em si mesma: as civilizações. As fronteiras das civilizações 
eram fronteiras mais socioculturais que político-militares, como no caso dos impérios. China, Índia e Europa eram, provavelmente, exemplos de sistemas macrossociais (= sociedades) cujas unidades eram definidas a partir de fronteiras socioculturais.

Nos últimos séculos, as inter-relações entre as regiões mundiais intensificaram-se enormemente, especialmente como resultado da colonização de outros continentes e suas sociedades por impérios europeus. A sociedade mundial surge lentamente dessa crescente interdependência como espaço sociocultural que inclui toda socialidade e comunicação nos limites deste sistema societal singular. 0 surgimento da sociedade mundial se expandiu especialmente pela emergência de sistemas de função global, tais como a economia, a política, a religião, as ciências e outros, sistemas mundiais que incluem todas as variedades de comportamento econômico, regimes políticos, crenças religiosas e práticas científicas como variedades internas desses sistemas de função global. Nesse sentido, pode ser dito que a ascensão da sociedade mundial e a gênese dos sistemas de função global são o mesmo processo social.

\section{A povoação da terra \\ e o surgimento do Antropoceno}

A gênese da sociedade mundial está acoplada à história do Homo sapiens como a espécie hominídea que conseguiu povoar todos os espaços naturais e coexistir com todas as ecologias naturais que existem na Terra. Houve uma variedade de espécies hominídeas ao longo de milhões de anos. Mas, no decorrer dos últimos 70 mil anos, os Homo sapiens originários de uma pequena região na África Oriental (próxima ao Lago Tanganyika) lograram prevalecer e extinguir todos os remanescentes das espécies hominídeas anteriores. A unidade de apenas uma espécie humana se tornou precondição e precursora da unidade posterior da sociedade mundial. Existe ainda outra unidade implícita, a "unidade psicológica da humanidade", como os antropólogos do século XIX começaram a chamá-la (Köpping, 2005), que estreita o espaço de alternativas comportamentais esperadas, facilitando a expansão da duração potencial da sociedade.

Além dessas condições biológicas e psicológicas, existe uma similaridade notável entre as instituições básicas de todas as sociedades humanas. Elas são todas baseadas em pequenos grupos nos quais o conhecimento sobre o parentesco pode ser pressuposto. Os humanos sabem a forma em que são relacionados uns com os outros - quem é parente, não parente, ou estranho. No lado mais material, em 
todas as sociedades humanas existem ferramentas de pedra e, provavelmente, de madeira, e outra (quase) universalidade surpreendente é o uso de pigmentos para representações pictóricas simbólicas. Ademais, existe a universalidade da linguagem e da comunicação - e o surgimento do mundo institucional ao redor da morte. Todas as sociedades humanas sepultam seus membros mortos; isso está conectado à experiência humana da fronteira entre a vida e a morte, demarcada por uma transição irreversível, e à morte de outros humanos e animais como um ato intencional e não simplesmente como efeito colateral de uma disputa violenta. O conhecimento da morte e as instituições ao redor da morte são, por fim, relacionadas ao surgimento de memórias socioculturais: a preservação da memória dos mortos, o conhecimento sobre a irreversibilidade da perda, e, em muitas sociedades, a vingança pela morte dos membros perdidos, aplicada àqueles que foram responsáveis por sua morte, podendo-se, até mesmo, efetivar essa vingança após períodos muito longos de tempo. Os horizontes espaciais e temporais da conduta da vida humana se expandem, formando outro aspecto da formação da sociedade.

O povoamento contínuo de novos espaços físicos sobre a Terra pelo Homo sapiens - que originalmente era um animal fisicamente inferior a muitos outros, e, por isso, necessitava de ferramentas e armas para defesa e sobrevivência - ao longo do tempo mudou as condições de vida de praticamente todas as formas de vida animal e vegetal existentes na Terra. O Homo sapiens tornou-se uma espécie globalmente dominante como nenhuma outra havia sido, e seus sistemas sociais e tecnologias, e seus efeitos cumulativos finalmente começaram a mudar até mesmo os parâmetros fisioquímicos do planeta em que a vida animal e vegetal evoluiu. "Antropoceno" tem sido aceito como o termo definidor de época para essa influência crescente dos sistemas sociais em todas as formas de vida, suas ecologias, e nos parâmetros fisioquímicos da Terra. É fácil ver que o "Antropoceno" é, em um aspecto, somente outra palavra para a condição que chamamos de "sociedade mundial". Em outros aspectos, é uma formulação para a realidade físico-tecnológica massiva da sociedade mundial, que contrasta drasticamente com a aparente leveza de suas comunicações. E é também um aspecto do argumento aqui apresentado sobre certos universais biológicos, psicológicos e socioculturais dos sistemas sociais humanos que relativiza a novidade da "sociedade mundial" como uma condição inesperada. A partir da universalidade de muitas precondições da sociedade mundial é possível deduzir que a realização posterior de uma sociedade mundial moderna se tornou, de alguma forma, provável logo da primeira vez que a preponderância de culturas do Homo sapiens se estabeleceu no planeta. 


\section{Evolução sociocultural}

Outra perspectiva sobre as transições de longo prazo acima analisadas é a de que elas podem ser atribuídas à invenção pelos hominídeos de um processo mundial que chamamos de evolução sociocultural (Blute, 2010; Boyd \& Richerson, 1985; Campbell, 1988; Hodgson \& Thorbjorn, 2010; Richerson \& Boyd, 2005). A evolução sociocultural é análoga à evolução biológica, sendo, no entanto, claramente distinta da mesma. Tanto a evolução biológica como a sociocultural são processos de transmissão de informação, e ambas tratam do armazenamento, da propagação, variação e reprodução seletiva de unidades de informação, e essas semelhanças identificam ambos os processos como genuínos processos evolucionários. Fora isso, são claramente diferentes. Na evolução biológica, é sempre o genoma (vegetal, animal) que funciona como o mecanismo de armazenamento; na evolução sociocultural temos as memórias culturais ou individuais. O mecanismo de transmissão se dá pelos genes no caso da evolução biológica; na evolução cultural, é baseada na comunicação e em tipos específicos de comunicação, como, por exemplo, os atos comunicativos do ensino e aprendizagem. A variação surge na evolução biológica a partir de mutações genéticas ou pela recombinação de genes (no caso da reprodução sexuada); já no caso da evolução sociocultural, se dá por atos de inovação social, pela negação implícita ou explícita de expectativas estabelecidas e em sistemas de conflito que intensificam as negações. Finalmente, temos os mecanismos de seleção. Na evolução biológica, a sobrevivência seletiva de organismos com características inovadoras é decisiva, além de outros níveis de seleção (Campbell, 1970); na evolução sociocultural existem muitos níveis de seleção (e a sobrevivência seletiva de sociedades inteiras e suas instituições pode ser importante nas sociedades de caçadores/coletores), mas basicamente a seleção sociocultural trata da reprodução seletiva de unidades sociais elementares (expectativas, símbolos, memes, rotinas) na comunicação.

O que é interessante na evolução sociocultural é que - como no caso da evolução biológica - a evolução sociocultural é claramente um processo mundial. Em outras palavras, quando trabalhamos com a evolução sociocultural, temos que utilizar uma perspectiva teórica que contradiga a impressão que a sociedade mundial é um surgimento tardio de tempos muito recentes. É claro que podem existir separações entre as regiões do mundo, até mesmo por milhares de anos, como provavelmente aconteceu em relação à separação das Américas do mundo eurasiático, até a "redescoberta" das Américas em torno de 1500. Depois dessa redescoberta, estabelece-se novamente um mundo único no qual a evolução sociocultural, como processo, continuou, produzindo novas expectativas e comportamentos e conservando apenas alguns deles em um espaço de possibilidades que conectava as regiões do mundo. E, é claro, havia sido um mundo único anteriormente. 
* No original em inglês connectivity e connectedness ( $n$. do t.).
Nos processos evolutivos, o isolamento e a separação sempre são, além da dupla fundamental da variação e seleção, os mais importantes mecanismos. Na evolução biológica, a separação/isolamento é responsável pela diferenciação de novas espécies animais e vegetais (Mayr, 1999). Na evolução sociocultural, o isolamento e a separação geram as muitas formas de diferenciação social (segmentação, estratificação, centro/periferia, diferenciação funcional) e a autonomia semipermanente de cada sistema social diferenciado, a qual sempre se baseia no uso de alguma das formas de diferenciação social (Stichweh, 2007b).

\section{Complexidade global e diferenciação funcional}

Na sociedade contemporânea existem muitos termos para a complexidade da sociedade mundial, todos formam uma parte importante do vocabulário de um sistema social global. Há, primeiramente, um termo que significa as relações simétricas de codependência entre unidades sociais (Olds, 1992). A sociedade mundial é, então, uma condição histórica que expande qualquer unidade social. Em princípio, qualquer uma pode estar inter-relacionada a qualquer outra. Ao mesmo tempo, as inter-relações entre unidades são sempre seletivas e, por meio dessa seletividade, surgem sentidos e estruturas. É possível entender esse interesse na inter-relação como um giro para uma compreensão relacional do mundo, um giro para o qual o surgimento de numerosas teorias de rede é um indicador, provavelmente o mais proeminente (Barabási, 2003). Um segundo termo relevante, porém diferente, é a conectividade (em alguns autores "conexão")* para a qual proponho uma interpretação que observa a conectividade como assimetria nas relações entre unidades (Subrahmanyam, 2005; Van Dijck, 2013). Uma segunda unidade social se conecta a algo que foi produzido anteriormente por uma primeira unidade. Isso quer dizer que há uma sequência temporal embutida nas relações de unidades sociais. Essas relações de conectividade estabelecem os processos sociais no tempo. E a conectividade parece significar que eventos remotos podem ser conectados uns aos outros. Um terceiro termo que tem de ser adicionado ao nosso vocabulário é ubiquidade (Buchanan, 2002). Esse conceito não se refere a relações, mas sim a repetições. Algumas unidades sociais são ubíquas na sociedade mundial. Esse entendimento é primeiramente sobre a universalidade espacial. As respectivas unidades e os eventos acoplados a elas podem ocorrer em qualquer lugar, vez após vez. Isso implica em um entendimento espacial do ser possível em qualquer lugar, mas adiciona a implicação temporal de que acontece vez após vez.

A forma mais importante de entender a complexidade social na sociedade global é a diferenciação funcional. Os sistemas de função combinam uma especificação 
funcional do sentido com a extensão global de seus horizontes comunicativos. Em algumas ocasiões, a diferenciação de perspectivas funcionais é idêntica ao processo histórico da globalização. A decomposição do mundo que é escolhida ao focarmos problemas de crença religiosa ou de verdade científica, justiça legal, lucratividade econômica etc., se alguém realmente assume uma dessas perspectivas, tolera restrições espaciais regionais - e nessa coevolução da diferenciação funcional e da sociedade mundial consiste a relevância revolucionária da especificação funcional e da concentração na gênese da sociedade mundial.

Claramente, existem muitos outros sistemas sociais além dos sistemas de função, como, por exemplo, interações, organizações, grupos sociais e outros candidatos. Eles não precisam ser globais e muitas vezes não o podem ser. Mas todos eles estão relacionados a sistemas de função, e os sistemas de função disponibilizam para eles a possibilidade de criar conexões com a sociedade mundial. Essa disponibilidade universal de elos com os contextos globais é a realização específica dos sistemas de função, definindo a sua relevância.

\section{As revoluções da inclusão e a relevância universal dos sistemas de função}

Os sistemas de função remontam as invenções semânticas e estruturais que, em alguns casos, foram construídas há dois mil anos (por exemplo, o Direito Romano ou a gênese das religiões e filosofias da Era Axial).

Mas os sistemas de função realizam sua forma moderna com base nas revoluções inclusivas que começaram na segunda metade do século XVIII: a revolução democrática, a revolução industrial, a revolução educativa, a revolução científica (Parsons \& Platt, 1974). Quando dizemos que uma revolução é inclusiva, isso significa que uma relevância funcional que anteriormente poderia ser um fenômeno societal muito pequeno adquire um novo tipo de universalidade social por meio do alcance potencial de quase todos os indivíduos humanos em sua abrangência. Vou ilustrar brevemente essa ideia fazendo referência aos quatro casos mencionados (e é obvio que existem mais do que esses quatro casos):

i. Revolução industrial ou econômica. Desde a segunda metade do século XVIII, as economias europeias foram os primeiros casos de grandes sistemas econômicos que escaparam da armadilha malthusiana de que o aumento populacional leva à pauperização de segmentos crescentes da população. Ao invés deste fenômeno clássico, na Europa surgiram economias em que o crescimento populacional virou a 
força motriz de um crescimento econômico que era ainda mais rápido que o crescimento populacional (Maddison, 2005; North \& Thomas, 1973). Duzentos anos depois dessa transição, que foi um fenômeno regional nas economias europeias, a revolução inclusiva da economia permanece acontecendo. Ainda existe um número significativo de populações no mundo que são marginais à economia mundial, tanto em termos de sua participação na força de trabalho global quanto em sua relevância como contribuidores às demandas econômicas globais.

ii. Revolução democrática. A partir do final do século XVIII, a democracia tornou-se, pela primeira vez na história, uma opção realista como regime político aceitável. Novamente, existe uma revolução inclusiva por trás desse fenômeno. Os sistemas políticos da sociedade moderna são cada vez mais baseados na inclusão de todos, primeiramente como beneficiários dos feitos e resultados dos processos políticos nos quais estão incluídos por meio das ideias sobre nação. Em segundo lugar, e de forma ainda mais importante, a inclusão se refere aos direitos e possibilidades de participação ativa na tomada de decisões políticas como detentores dos votos políticos e em muitas outras situações e papéis. A extensão desses direitos de participação é o cerne da revolução inclusiva da sociedade moderna. Esses direitos de participação são garantidos a indivíduos e/ou às novas coletividades dos sistemas políticos modernos, agrupamentos que já não são estratos heterogêneos ou Estados, sendo agora constituídos como coletividades inclusivas chamadas de "o povo" ou "a nação". A mistura e o peso relativo da inclusão individual e coletiva diferem ao longo do tempo e entre países e tipos de regime (Judson, 2016). Mas a referência à relevância da inclusão universal é compartilhada até mesmo com muitos regimes autoritários que muitas vezes preferem se descrever como "democráticos" (por exemplo, "democracia popular" no caso de muitos regimes comunistas). Nesse sentido, pode ser dito que a revolução democrática é um fenômeno mundial e que a distinção bipolar entre democracia e autoritarismo simplesmente descrevem dois subtipos daquela (Ahler \& Stichweh, 2017).

iii. Revolução educativa. Se observarmos a tradição europeia desde a Idade Média, as escolas primárias e secundárias e as universidades foram, por centenas de anos, em sua maioria pequenas e fenômenos de nicho, muitas vezes relevantes na educação de elites, mas somente delas. Desde o século XVIII, é possível observar uma universalização progressiva dos diferentes níveis da escolarização, primeiramente como 
um desenvolvimento europeu, depois mundial. Existiu algo parecido a uma universalização da educação primária no fim do século XVIII em alguns países europeus (especialmente os calvinistas - Escócia, Holanda); no final do século XIX, os Estados Unidos se tornam o primeiro caso assemelhado à universalização da escolarização secundária (incluindo meninas) (Goldin \& Katz, 2008). Na virada dos séculos XX e XXI, é possível observar índices muito elevados de inclusão na educação superior, que em alguns países (Coreia do Sul, Taiwan, Nova Zelândia) chegam a quase $100 \%$. Novamente, aqui vemos a relevância global dos diferentes níveis da escolarização sendo realizada por meio da revolução educativa como revolução inclusiva.

iv. Revolução científica. Existem conceitos bem estabelecidos em relação à revolução científica do século XVII e a assim chamada segunda revolução científica das décadas próximas ao ano 1800 (Bellone, 1980; Brush, 1988). Mas essas duas revoluções não tratam primariamente de inclusão universal, apesar de a diferenciação entre as disciplinas da ciência na segunda revolução científica ser obviamente acoplada a efeitos inclusivos (Stichweh, 1984; 1992). Mesmo assim, é possível argumentar que a disponibilização de papeis inclusivos para todos nunca surgiu no sistema global da ciência. Ao observar essa situação, propomos para a ciência o conceito de uma "revolução científica" (que provavelmente deveríamos chamar de "terceira revolução científica") que começa somente nos séculos XX-XXI, que realizam a inclusão global de forma diferente do que os demais sistemas de função. A transformação em seu cerne não se dá com a disponibilização de papeis inclusivos para todos. Ao invés disso, essa transformação é caracterizada por uma enorme expansão do espaço de problemas que a pesquisa científica pode lidar. O efeito principal dessa revolução é que não existe nenhum aspecto da prática de viver na sociedade contemporânea que não seja afetada por percepções e descobertas baseadas na pesquisa científica. Portanto, a inclusão global na ciência não se dá na forma de papéis inclusivos na ciência, mas sobretudo na relevância dos sistemas de conhecimento científico em quase todos os aspectos da vida, algo que não pode ser negado facilmente. É desta relevância do conhecimento científico que é possível derivar o seu interesse para todos, que têm, então, boas razões para observar seu desenrolar.

Poderíamos estender esse argumento, ao observarmos outras revoluções inclusivas e seus efeitos na constituição do sistema mundial. A lógica é similar: existem 
* Eigenstructures (autoestruturas) pelo prefixo alemão eigen (auto), também associado a noções matemáticas de autovetores e autovalores de matrizes quadradas. nichos de comunicação altamente especializadas em algumas regiões do mundo, os quais, ao incluírem cada vez mais novas regiões, novos tipos de coletividades, e ao criarem, fazendo da individualidade uma instituição-cerne da sociedade, tornam-se parte constitutiva da sociedade mundial, e como tal, ao fim e ao cabo, adquirem responsividade a todos os aspectos de seus ambientes sociais. A responsividade significa um tipo de competência diagnóstica que utiliza perspectivas altamente especializadas para redefinir problemas sociais externos. Então existem variantes interessantes nesses processos, como o caso que a ciência ilustra. A ciência é mais um sistema de função com uma responsividade de longo alcance em seus ambientes sociais, assim realizando possibilidades universais de inclusão para todos.

\section{Teoria das autoestruturas*}

Escrever sobre a diferenciação funcional necessariamente significa analisar uma das autoestruturas da sociedade mundial. As autoestruturas são estruturas da sociedade que se relacionam com a sociedade mundial por meio de intensificação recíproca. Elas suscitam a sociedade mundial, e o sistema mundial emergente reforça suas próprias precondições dando a essas estruturas vantagens evolucionárias em comparação a outras estruturas da sociedade (Stichweh, 2007a).

Dentre as autoestruturas, a diferenciação funcional é a estrutura definidora da sociedade mundial e da modernidade. Desde 1750, temos uma história de 250 anos com transições significativas (revoluções inclusivas a mudança para sistemas globais com responsividade global) e adições significativas (mídia de massa, esportes, acréscimo de inquietudes sobre enfrentamento a um "sistema de doenças") e um futuro em aberto. Mas existe um crescimento enorme em complexidade estrutural com a adição de outras autoestruturas.

Existem redes globais que, tal como as chamadas redes de pequeno mundo (ou seja, redes sem escala), combinam o princípio de inter-relação direta e indireta entre um grande número de nodos de rede (bilhões de indivíduos, bilhões de websites) com distâncias surpreendentemente curtas entre quaisquer dois nodos dentre esses bilhões. Tal "pequeno mundo" sempre pode ser descrito pelo paradoxo criado em razão de ser, por um lado, um mundo (ou seja, inexaurível, não entendido facilmente) e, ao mesmo tempo, "pequeno", já que qualquer um dos nodos dessa rede pode ser atingido a partir de qualquer outro em apenas poucos passos (Easley \& Kleinberg, 2010).

Uma das características sociológicas marcantes das redes de pequeno mundo é que elas combinam as propriedades não hierárquicas da lateralidade (não existe 
uma hierarquia formal de níveis) com formas de hierarquia e desigualdade específicas às redes. Diferentes nodos na rede são caracterizados por números 'bastante diferentes de vínculos que têm (sem aglomeração em torno de um valor central de ligações). Essa é uma forma notável de desigualdade que reforça a si mesma por mecanismos de "ligação preferencial" que fazem com que seja provável que novas ligações sejam endereçadas aos nodos que já tem uma quantidade significativa de ligações. Os nodos privilegiados dessa forma ganham centralidade na rede, o que implica que muitos processos de informação sejam roteados por meio desses nós centrais na rede. Uma interpretação sociológica desses nós centrais adicionaria que o roteamento de muitas comunicações por meio de um nó o impregna de poder (Burt, 1992). Eles são "guardiões". É necessário invocá-los e conseguir seu consentimento para obter acesso a certos recursos e informações. O problema de acesso a recursos e informação muitas vezes aponta terceiros com os quais não se tem ligações próprias, portanto, os guardiões se fazem necessários, afirmando seu poder. Existe uma forte relação matemática entre essas hierarquias nas redes de pequeno mundo e as distâncias impressionantemente curtas que são observadas mesmo em redes extensas.

A originalidade e relevância sociológica na forma da formação estrutural chamada de redes de pequeno mundo será visível. Dentro de todo sistema de função sempre existirão muitas redes de pequeno mundo. Por exemplo, ao estudar a diferenciação interna de uma disciplina científica é possível observar as redes estruturais de cooperação e coautoria internas ou mesmo analisar as estruturas conceituais de uma disciplina como uma rede cognitiva. Mas se quisermos observar a unidade geral de uma disciplina científica e suas relações com outras disciplinas em seu ambiente científico, a análise de redes não parece ser o melhor instrumento. Para poder analisar a unidade e a diferenciação internas e ambientes externos a uma disciplina, é necessário o uso da teoria de diferenciação funcional e suas visões em relação à diferenciação interna da ciência em uma pluralidade de sistemas de comunicação disciplinares.

Uma terceira autoestrutura da sociedade mundial é a organização formal. As organizações, como sistemas, são baseadas na adesão. Para cada indivíduo que queira pertencer a uma organização, deve haver uma decisão sobre sua inclusão como membro. Não somente a inclusão de membros é baseada em decisões, todas as demais operações comunicativas internas às organizações resultarão em uma decisão a ser tomada. Todas as decisões tomadas por uma organização funcionam, então, como premissas para conectar operações e para futuras decisões, baseadas em decisões anteriores. É essa habilidade de trabalhar com base em uma sequência de decisões que distingue a organização dos sistemas de função e das redes, que não podem tomar decisões. 
A globalidade das organizações modernas - outro atributo definidor - surge do fato de que é relativamente fácil replicar as organizações e suas rotinas constitutivas (Nelson \& Winter, 1982). É possível estabelecer empreendimentos econômicos, igrejas, clubes esportivos, hospitais e universidades em qualquer lugar do mundo. São necessárias adaptações locais e regionais para tal, mas a própria forma de institucionalizar essas adaptações pode virar uma rotina organizacional em si. Consequentemente, é possível observar organizações que existem em formas similares em todas as regiões do mundo. E é possível separar a mesma macro-organização mundialmente orientada em dezenas ou mesmo centenas de subsidiárias localizadas regionalmente, o que assegura a presença dessa macro-organização em qualquer lugar do mundo. Dentre as suborganizações de uma macro-organização e entre as organizações com um foco temático na perspectiva de um sistema de função surgem as redes globais de organizações. Isso enfatiza a complementaridade e intensificação recíproca destas três formações de estrutura: o sistema de função, a rede de pequeno mundo e a organização.

A quarta autoestrutura da sociedade mundial é a comunidade epistêmica. A comunidade epistêmica, mais que as primeiras três, incorpora o fato de a sociedade mundial do presente ser uma "sociedade do conhecimento" (Stichweh, 2014). As comunidades epistêmicas incluem todos aqueles que compartilham um certo repertório de premissas normativas e cognitivas constituintes da comunidade. Esses participantes das comunidades não necessitam estar organizados nem estabelecer uma rede de pequeno mundo, já que para eles a natureza vinculativa das normas e cognições é assegurada pela observação recíproca dos participantes e não por ligações de cooperação e trocas sociais. Talvez possamos até dizer que uma comunidade epistêmica se mantém unida mais fortemente por uma solidariedade "mecânica" das comunidades do que por uma solidariedade "orgânica" dos sistemas de função e das redes de pequeno mundo (Durkheim, 1973). Um caso teste para o conceito de comunidade epistêmica poderia ser a comunidade epistêmica mundial de jogadores de xadrez. Ela não faz parte de um sistema de função - não é, por exemplo, um subsistema do sistema de função "esporte", já que a aceitação do xadrez na categoria esportes é mais honorária que real. O xadrez é apenas parcialmente organizado; a maior parte dos jogadores de xadrez do mundo provavelmente não são membros de um clube ou de qualquer outra organização. E a comunidade de todos os jogadores de xadrez não é idêntica à rede de pequeno mundo daqueles jogadores que competem entre si em jogos on-line na internet. Portanto, o xadrez parece ser primeiramente uma comunidade epistêmica unida pelas regras e por observações de aberturas, finais e jogos integrais. No máximo, é possível reivindicar que o xadrez seja um "pequeno" sistema de função. Mas para conseguir realizar essa reivindicação, o xadrez precisaria de uma universalidade 
temática (a projeção instrutiva e criativa das perspectivas do xadrez em qualquer contexto de significado na sociedade) e uma revolução da inclusão.

A quinta autoestrutura da sociedade mundial é o "sistema de interação global". Os sistemas de interação global surgem com base nos sistemas que foram chamados de "ordem de interação" (Goffman, 1983), "sistemas sociais simples" (Luhmann, 1975) ou "encontros" (Goffman, 1961) e pela combinação desses sistemas fortemente localizados definidos pela copresença visual de todos os participantes com a inclusão virtual tecnologicamente disponibilizada de qualquer outra pessoa. Existe uma série de variações: áudio-comunicações (telefone), vídeo-comunicações (Skype etc.), escrita sincronizada (chats). Essas formas podem ser praticadas como formas autossuficientes ou podem ser integradas em sistemas clássicos de interação baseados na presença. Um dos surgimentos mais notáveis é a possibilidade de que cada indivíduo participe simultaneamente de uma pluralidade desses sistemas de interação global.

Esta é, certamente, uma lista provisória de autoestruturas. A evolução sociocultural provavelmente vai, ao longo do tempo, adicionar novas estruturas de construção da sociedade. Também mudarão as autoestruturas existentes e, finalmente, serão desenvolvidos novos sistemas de função. É possível levantar a hipótese de que sempre existam novos sistemas de função sendo construídos, que talvez possam se chamar de "pequenos sistemas de função" (além do xadrez, já mencionado acima, os jogos de computador podem ser um exemplo ainda melhor de um "pequeno sistema de função", apesar de, em termos numéricos, já constituírem um sistema importante). Apenas alguns vão adquirir relevância social universal (com uma revolução da inclusão e a expansão em direção à constituição mundial), característica do sistema de função.

Existe um último candidato, que vamos mencionar apenas rapidamente nesse artigo (uma reflexão mais extensa sobre o tema, Stichweh, 2008). Falamos da encenação de "eventos mundiais" como as exibições mundiais (desde 1851), as Olimpíadas (desde 1896), as conferências e cúpulas mundiais (de política e em outros domínios funcionais), feiras de arte (desde 1967)(Morgner, 2014) e feiras internacionais de artes, economia ou de tantos outros casos de eventos mundiais. Os eventos mundiais são um caso interessante da autotematização e auto-organização da sociedade mundial. Eles estão baseados em quatro características principais: temáticas funcionalmente definidas (operando, de alguma forma, na linha da diferenciação funcional); são caracterizados por serem locais (a maior parte deles é vinculada a cidades específicas); por limitações temporais (duram alguns dias ou, no máximo, algumas semanas); e por inclusão global (todo mundo pode participar, 
ou por presença pessoal, ou como observador, através das mídias). Finalmente, é possível apontar a "significância mundial" do que acontece num evento mundial para distingui-los de eventos mais locais.

\section{Mecanismos da globalização}

Existem vários mecanismos sociais básicos que são os mecanismos geradores da complexidade social (inter-relação, conectividade, ubiquidade) característica da sociedade mundial.

Há, primeiramente, a "comunicação" que é a operação elementar funcionando como a base operativa de todos os eventos na sociedade humana e, por implicação, na sociedade mundial. A comunicação é responsável pela seletividade da transferência de informação (nem toda informação disponível para um participante é comunicada em sociedade) dentre díades de processadores (toda sociedade consiste em díades, tríades e arranjos mais complexos de processadores). Processadores são, em sua maior parte, indivíduos humanos, mas outros candidatos - deuses, ancestrais, outras espécies animais, robôs - podem entrar em cena. Na comunicação, os processadores são relacionados pela capacidade de alcance, conectividade, mídia de comunicação (assegurando o alcance global), intencionalidade (ao selecionar informações para transferência) e entendimento (por segundos, terceiros processadores). O surgimento da sociedade mundial pode ser estudado como tendo emergido das transformações nesses componentes da comunicação.

O segundo mecanismo da globalização é a migração. Migração significa a transferência voluntária ou involuntária, parcial ou completa de estruturas sociais (no sentido de variações, expectativas, comportamentos) pelo deslocamento espacial de migrantes. No processo do primeiro povoamento do planeta pelo Homo sapiens (70.000-10.000 a.C.) a migração era, claramente, o mais importante mecanismo de globalização. Hoje, foi excedida nesse papel pela comunicação baseada nas mídias (Stichweh, 2016: 189201). Ainda assim, os migrantes que chegam como estranhos em algum outro lugar são eficientes em transportar variações de expectativas e comportamentos.

A globalização e os efeitos de difusão dependem de comunicação (as variações de sentido transportadas precisam ser comunicadas). E elas dependem de observação. Mesmo se os migrantes não comunicarem seu conhecimento, os locais vão observá-los e aprender com eles pela observação. Observar significa aplicar distinções a realidades que se espera entender melhor ao criar essas mesmas distinções. A observação esteve relacionada, por um longo tempo, a locais estritamente circunscritos. Por meio das mesmas mídias eletrônicas que transformam a comunicação, a 
observação é separada de locais específicos, tornando-se observação mundial. Em qualquer lugar no mundo é possível observar filmes japoneses ou jogos de futebol ingleses ou mercados de ação mundiais. Em algum momento todas essas observações terão de ser incluídas nos processos de comunicação (ou elas não entrariam na sociedade e, portanto, não teriam relevância social). Mas essa introdução da observação nas comunicações acontece seletivamente e com algum atraso. A partir dessas considerações, é fácil observar, por exemplo, como a comparação global de alternativas com base em possibilidades observacionais globais é o terceiro mecanismo da globalização.

Finalmente, temos de falar sobre o conhecimento. O conhecimento local, e então global, é o resultado cumulativo da operação da comunicação, migração e observação. O conhecimento estabiliza os resultados desses três mecanismos. Poderíamos chamar o conhecimento do mecanismo de memória sociocultural. E o conhecimento se torna globalizado. O conhecimento que é descoberto e é considerado relevante em algum lugar do mundo pode, na sociedade atual, tornar-se conhecimento

relevante em qualquer parte do mundo. É possível conhecer cada vez mais sobre as alternativas que são disponíveis em uma perspectiva mundial e é possível tomar decisões significativas tendo em vista esse pano de fundo. É claro que também é possível ser ignorante de partes significativas do conhecimento disponível, bem como é possível experimentar algo de forma "cega". Mas, no momento seguinte, a alternativa escolhida cegamente entra na circulação mundial das ações de conhecimento. Nesse entendimento, a evolução cultural é precisamente um processo mundial de conhecimento em que a acessibilidade global do conhecimento se torna cada vez mais visível e em que, ainda assim, as reativações da "cegueira" acontecem com frequência. Esses níveis de seleção (provavelmente existem outros) se entrelaçam (Campbell, 1988), o que significa que eles constroem uma ordem hierárquica da acumulação e transformação incessante do conhecimento global no sistema da sociedade mundial.

\section{Referências}

AHLERS, Anna L.; STICHWEH, Rudolf. The bipolarity of democracy and authoritarianism. Value patterns, inclusion roles, and forms of internal differentiation of political systems. Bonn: FIW Working Paper 09, , 2017. Disponível em: <https://www.fiw. uni-bonn.de/publikationen/FIWWorkingPaper>.

BARABÁSI, Albert-László. Linked. How everything is connected to everything else and what it means for business, science and everyday life. New York: Plume, 2003. 
BELLONE, Enrico. A world on paper. Studies on the second scientific revolution. Cambridge (MA): The MIT Press, 1980.

BLUTE, Marion. Darwinian sociocultural evolution: solutions to dilemmas in cultural and social theory. Cambridge (UK): Cambridge University Press, 2010.

BOYD, Robert; RICHERSON, Peter J. Culture and the evolutionary process. Chicago (IL): University of Chicago Press, 1985.

BRUSH, Stephen G. The history of modern science: a guide to the second scientific revolution, 1800-1950. Ames (IA): Iowa State Press, 1988.

BUCHANAN, Mark. Ubiquity: why catastrophes happen. New York: Crown, 2002.

BURT, Ronald S. Structural holes. The social structure of competition. Cambridge (MA): Harvard University Press, 1992.

CAMPBELL, Donald T. Methodology and epistemology for social science. Chicago (IL): University of Chicago Press, 1988.

- Natural selection as an epistemological model. In: NAROLL, Raoul; COHEN, Ronald (Eds.). A handbook of method in cultural anthropology, p. 51-85, Garden City (NY): Natural History Press, 1970.

DURKHEIM, Émile. De la division du travail social. Paris: Presses Universitaires de France, 1973 [1893].

EASLEY, David; KLEINBERG, Jon. Networks, crowds, and markets. reasoning about a highly connected world. Cambridge (UK): Cambridge University Press, 2010.

ENCYCLOPAEDIA BRITANNICA. "Society". in Encyclopaedia Britannica, v. 3. Edinburgh: Britannica, 1771.

GOFFMAN, Erving. The interaction order. American Sociological Review, v. 48, n. 1, p. 1-17, 1983.

- Encounters: two studies in the sociology of interaction. Indianapolis (IN): Bobbs-Merrill, 1961.

GOLDIN, Claudia; KATZ, Lawrence F. The race between education and technology. Cambridge (MA); London: The Belknap Press of Harvard University Press, 2008.

HODGSON, Geoffrey M.; THORBJORN, Knudsen. Darwin's conjecture. The search for general principles of social and economic evolution. Chicago (IL): University of Chicago Press, 2010. 
JUDSON, Pieter M. The Habsburg Empire. A new history. Cambridge (MA): The Belknap Press of Harvard University Press, 2016

KÖPPING, Klaus Peter. Adolf Bastian and the psychic unity of mankind. the foundations of anthropology in nineteenth century germany. Münster: Verlag, 2005.

LUHMANN, Niklas. Einfache Sozialsysteme. In: LUHMANN, Niklas (Ed.). Soziologische Aufklärung 2, p. 21-38. Opladen: Westdeutscher Verlag, 1975.

MADDISON, Angus. Growth and interaction in the world economy. the roots of modernity. Washington (DC): The AEI Press, 2005.

MAYR, Ernst. Systematics and the origin of species from the viewpoint of a zoologist. Cambridge (MA): Harvard University Press, 1999 [1942].

MORGNER, Christian. The evolution of the art fair. Historical Social Research/Historische Sozialforschung, v. 39, n. 3, p. 318-336, 2014.

NELSON, Richard R.; WINTER, Sidney G. An evolutionary theory of economic change. Cambridge (MA): The Belknap Press of Harvard University Press, 1982.

NORTH, Douglas C.; THOMAS, Robert Paul. The rise of the Western World: a new economic history. New York: Cambridge University Press, 1973.

OLDS, Linda E. Metaphors of interrelatedness: towards a systems theory of psychology. New York: State Universioty of New York Press, 1992.

PARSONS, Talcott; PLATT, Gerald M. The american university. Cambridge (MA): Harvard University Press, 1974.

RICHERSON, Peter J.; BOYD, Robert. Not by genes alone. How culture transformed human evolution. Chicago: University of Chicago Press, 2005.

STICHWEH, Rudolf. Inklusion und Exklusion. Studien zur Gesellschaftstheorie (2. erweiterte Auflage). Bielefeld (DE): Transcript, 2016.

Wissensordnungen und Wissensproduktion im 21. Jahrhundert. Merkur, v. 68, n. 4, p. 336-344, 2014.

- Zur Soziologie des Weltereignisses. In: NACKE, Stefan; UNKELBACH, René; WELTEREIGNISSE, Tobias Werron (Eds.). Theoretische und empirische Perspektiven, p. 17-40. Wiesbaden (DE): VS Verlag für Sozialwissenschaften, 2008.

The Eigenstructures of world society and the regional cultures of the world. In: ROSSI, Ino (Ed.). Frontiers of globalization research: theoretical and methodological approaches, p. 133-49. New York: Springer, 2007a. 
- Evolutionary theory and the theory of world society. Soziale Systeme, v. 13 p. 528-542, 2007b.

—. Zum Gesellschaftsbegriff der Systemtheorie: Parsons und Luhmann und die Hypothese der Weltgesellschaft. In: HEINTZ, Bettina; MÜNCH, Richard; TYRELL, Hartmann (Eds.). Weltgesellschaft. Theoretische Zugänge und empirische Problemlagen, p. 174-185. Stuttgart (DE): Lucius \& Lucius, 2005.

- The sociology of scientific disciplines: on the genesis and stability of the disciplinary structure of modern sciene. Science in Context, v. 5, p. 3-15, 1992.

_. Zur Entstehung des modernen Systems wissenschaftlicher Disziplinen. Physik in Deutschland 1740-1890. Frankfurt (DE): Suhrkamp, 1984.

SUBRAHMANYAM, Sanjay. Explorations in connected history. Mughals and Franks. New Delhi: Oxford University Press, 2005.

VAN DIJCK, José. The culture of connectivity. a critical history of social media. Oxford (UK): Oxford University Press, 2013. 